\title{
Espaços de formação e circuitos profissionais no design por meio das trajetórias de Irene Ruchti e Fayga Ostrower
}

\section{Training spaces and professional circulations in design through the trajectories of Irene Ruchti and Fayga Ostrower}

\author{
Ana Julia Melo Almeida, Faculdade de Arquitetura e Urbanismo - Universidade \\ de São Paulo (FAUUSP) \\ ajuliamelo@usp.br
}

\author{
Maria Cecilia Loschiavo dos Santos, Faculdade de Arquitetura e Urbanismo - \\ Universidade de São Paulo (FAUUSP) \\ closchia@usp.br
}

\begin{abstract}
Resumo
A partir das atuações de Irene Ruchti e Fayga Ostrower, abordaremos a produção das artistas no campo do design durante as décadas de 1950 e 1960, por meio das relações que elas estabeleceram ao longo de suas carreiras nos espaços de formação e nos circuitos profissionais. Duas instituições foram centrais para a elaboração do pensamento e da atividade de design, o MASP, onde Irene foi aluna da Escola de Desenho Industrial, e o MAM Rio, em que Fayga atuou como docente no curso de Composição. O intuito deste artigo é considerar suas trajetórias em paralelo para investigar as condições sociais que possibilitaram a essas mulheres artistas os acessos aos espaços de trabalho e às práticas de design. Portanto, recortaremos nossa análise para uma fração da produção dessas artistas mais próxima ao design, que depois se concentrará na arte e na arquitetura.
\end{abstract}

Palavras-chave: História do design brasileiro, Mulheres e design, Estudos feministas, Espaços de formação, Circuitos profissionais.

\begin{abstract}
Through the work of Irene Ruchti and Fayga Ostrower, this article will approach the production of artists in the field of design during the 1950s and 1960s, analyzing the relationships they have established throughout their careers in training spaces and professional circulations. Two institutions are central to the elaboration of design idea and activity: MASP, where Irene was a student at the Escola de Desenho Industrial, and MAM Rio, where Fayga worked as a teacher in the Composition course. The purpose of this study is to consider their trajectories in parallel to investigate the social conditions that enabled these women artists to access workspaces and design practices. Therefore, we focus our analysis on a fraction of the production of these artists in the field of design, more than art and architecture.
\end{abstract}

Keywords: History of Brazilian design, Women and design, Feminist studies, Training spaces, Professional circulations. 


\section{Introdução}

Ao longo dos anos 1950 e 1960, o processo de institucionalização do design no Brasil está inserido em um cenário de modernização e industrialização, que se estrutura a partir das cidades do Rio de Janeiro e de São Paulo. É nesse contexto que dois espaços culturais ${ }^{1}$ atuaram como laboratórios na elaboração e propagação do pensamento moderno nas artes, no design e na arquitetura, por meio de um conjunto de atividades artísticas e pedagógicas: o Museu de Arte de São Paulo (MASP), fundado em 1947, e o Museu de Arte do Rio de Janeiro ${ }^{2}$ (MAM Rio), criado em 1948.

Por meio do surgimento do Instituto de Arte Contemporânea ${ }^{3}$ no MASP, estruturou-se a Escola de Desenho Industrial ${ }^{4}$, que funcionou entre os anos de 1951 e 1953. Em 1952, no MAM Rio, foram criados os cursos livres em arte e arte aplicada e se iniciou, a partir disso, uma ampla discussão em torno da Escola Técnica de Criação (ETC). Ela não irá se concretizar no museu, mas contribuirá para o surgimento da Escola Superior de Desenho Industrial (Esdi), em 1962, e do Instituto de Desenho Industrial (IDI), em 1968, ligado ao MAM Rio.

Essas instituições tornaram-se fundamentais para a formação e consolidação dos profissionais, que na época atuavam em uma constante interação e colaboração entre artistas, arquitetos e designers. Essa ideia do museu como espaço de discussão e de formação era um dos pilares do próprio pensamento moderno, que tinha como eixo de ação a constituição de um museu com caráter pedagógico, seja de profissionais, nas atividades de ensino, seja do público por meio das exposições didáticas.

Nesse contexto, o surgimento dos espaços de formação nos museus de arte atrelados às premissas modernas contribuíram para a discussão e a redefinição das atividades de projeto no país. Esses aspectos repercutem também na criação do primeiro curso superior em Design, na Escola Superior de Desenho Industrial (Esdi), em 1962, que será utilizado como base para a

\footnotetext{
${ }^{1}$ Além deles, é importante mencionar o surgimento do Museu de Arte Moderna de São Paulo (MAM-SP), em 1948, e do Museu de Arte Moderna da Bahia (MAM-BA), em 1960. Ambos contaram com projeto em torno de escolas e cursos livres: o primeiro com os cursos livres em arte e história da arte e a Escola de Artesanato, com ateliês de formação em cerâmica e gravura. Já o MAM-BA elaborou a proposta de criação da Escola de Mestres e Projetistas, que não chegou a ser efetuada, dando continuidade a algumas ideias que já tinham sido apresentadas pelo IAC-MASP, mas nesse caso contaria com uma articulação com os artesãos locais. Assim como no MASP, a arquiteta Lina Bo Bardi também teve um papel central na elaboração das exposições e das atividades dessa instituição. Sobre a atuação da arquiteta na Bahia, ver mais em: Juliano Pereira (2008). A respeito da Escola de Artesanato no MAM-SP, ver mais em: Maria Luisa Távora (2017).

${ }^{2}$ O ano que consta no site oficial do MAM Rio para sua criação é 1948, ano em que foi assinada a ata inaugural. Porém, reconhecemos que a movimentação em torno da fundação do museu durou alguns anos. A pesquisadora Sabrina Sant'Anna (2008) aponta que a primeira exposição ocorreu em 1949 e a eleição do Conselho Executivo da instituição, em 1951. Portanto, alguns pesquisadores também adotam essas datas posteriores como marco para a fundação do museu.

3 O Instituto de Arte Contemporânea (IAC) foi criado em São Paulo em 1951, quatro anos após a fundação do MASP, e foi de grande importância para o campo do design, pois nele foi instalado o primeiro espaço de formação no Brasil a partir de uma orientação moderna. A Escola de Desenho Industrial, parte do Instituto, estruturada por Lina Bo Bardi e Pietro Maria Bardi, contribuiu de forma significativa para a institucionalização do campo, que ocorreria efetivamente na década seguinte (Lucy Niemeyer, 1997; Rafael Cardoso, 2005; Ethel Leon, 2006).

${ }^{4}$ A respeito da estruturação da escola e de seus integrantes, ver mais em: Ethel Leon (2006).
} 
propagação dos cursos na área nas décadas seguintes. Rafael Cardoso (2005) escreve que esses anos de experimentação entre o surgimento do IAC do MASP, em 1951, e a inauguração da Esdi ${ }^{5}$, em 1963, configuraram-se como um período de ruptura que inaugurou um novo paradigma de ensino e de exercício da profissão na área de design no país. A institucionalização do campo nesse contexto foi marcada pela implementação do pensamento moderno e teve, em grande parte, incentivos do poder público.

Além de importantes espaços para a consolidação do pensamento em design, as instituições culturais também atuaram como redes de sociabilidade. Neste artigo, analisamos a constituição dos espaços de formação e a maneira pela qual se configura sua relação com os circuitos profissionais e de legitimação no campo. Isso pode ser observado por meio de uma rede de profissionais envolvidos na implementação do design no Brasil ${ }^{6}$. Duas trajetórias nos parecem significativas para analisarmos as condições de acesso de mulheres artistas aos espaços de formação, aos circuitos profissionais e como essas redes de sociabilidade se constituíram nas práticas de design: Irene Ruchti, aluna da Escola de Desenho Industrial do IAC-MASP, e Fayga Ostrower, professora do curso de Composição no MAM Rio.

Irene Ruchti ${ }^{7}$ (1931-2020) iniciou sua formação no curso de Artes Plásticas no Instituto de Belas Artes (UFRGS), em 1947. No começo dos anos de 1950, ainda em Porto Alegre (RS), é convidada por Assis Chateaubriand para integrar a primeira turma da Escola de Desenho Industrial do IAC-MASP. Por este motivo, se mudou para São Paulo, onde permaneceu até o final da vida. Durante seu período de IAC, a artista conheceu Jacob Ruchti ${ }^{8}$, à época professor da instituição, com quem se casou e desenvolveu diversos trabalhos em parceria. A carreira de Irene no campo do design parte de projetos para interiores, produção de tecidos estampados e elaboração de cenário e figurino para o Ballet do IV Centenário de São Paulo (1954) para o paisagismo, área à qual se dedicou na maior parte de sua trajetória profissional.

Já Fayga Ostrower ${ }^{9}$ (1920-2001) migrou da Europa ao Brasil com a família em 1934. Ao se estabelecer no Rio de Janeiro, suas primeiras atividades profissionais foram como auxiliar de escritório e depois secretária em diversas empresas e indústrias. Em 1946, após uma

\footnotetext{
${ }^{5}$ A Escola Superior de Desenho Industrial (Esdi) foi criada em 1962 e implementada em 1963. A partir de sua criação, a escola terá uma grande repercussão nos currículos dos cursos em design e em sua propagação pelo país. Ver mais em: Lucy Niemeyer (1997); Rafael Cardoso (2005).

${ }^{6}$ No caso do MASP, podemos destacar a atuação de Lina Bo Bardi, Pietro Maria Bardi e Jacob Ruchti; no MAM Rio, Carmen Portinho, Niomar Moniz Sodré e Afonso Eduardo Reidy.

${ }^{7}$ Irene Ruchti (nome ao nascimento: Irene Ivanovsky) nasceu em Imbituba, Santa Catarina, em 11 de setembro de 1931. Passou a infância e o início da adolescência em Pelotas (RS), onde viveu até 1946.

${ }^{8}$ Jacob Ruchti (1917-1974) nasceu na Suíça, a família migrou para o Brasil no ano de 1919 e se estabeleceu na cidade de São Paulo. Em 1940, Jacob Ruchti concluiu o curso de Arquitetura pela Universidade Mackenzie. A trajetória do arquiteto e sua atuação na arquitetura moderna em São Paulo foram documentadas na pesquisa de mestrado de Valeria Ruchti (2011).

${ }^{9}$ Fayga Ostrower (nome ao nascimento: Fayga Perla Krakowski) nasceu em Lódz, na Polônia, em 14 de setembro de 1920. Em 1921, a família muda-se para Wuppertal (Alemanha). Já em 1933, a família de Fayga, na condição de imigrantes judeus, decide seguir para a Bélgica, onde permanece até conseguir visto para o Brasil. Em 1938, Fayga conheceu Heinz Ostrower na livraria Kosmos, no Rio de Janeiro, com quem se casou em 1941. Heinz Ostrower (1912-1992) nasceu em Jauer (Alemanha) em uma família de origem judaica. Devido a sua atuação política pelo socialismo, passou três anos preso na Espanha. Isso faz com que Heinz perca sua cidadania alemã. Em 1937, migrou para o Brasil, onde se estabeleceu na cidade do Rio de Janeiro. Essas informações também foram obtidas no Instituto Fayga Ostrower (IFO).
} 
aproximação no campo da arte por meio da Sociedade Brasileira de Belas Artes, Fayga decidiu abandonar o cargo de secretária-executiva na General Eletric para se matricular no curso de Desenho e Artes Gráficas da Fundação Getúlio Vargas (FGV). A partir de então, sua produção artística passa a ser a ocupação principal, produzindo ilustrações para diversos livros, revistas e jornais. Em 1953, Fayga é convidada a ministrar o curso de Composição ${ }^{10}$ no MAM Rio, atividade para a qual se dedicou por mais de 15 anos.

Para pensar nas trajetórias das duas artistas, investigando a complexidade das relações sociais presentes na atividade de design, tensionando o acesso aos espaços de formação, aos meios de trabalho, ao circuito das exposições e às possibilidades de carreiras no campo, temos como embasamento teórico os estudos feministas ${ }^{11}$, por meio de uma abordagem relacional. Nesse sentido, entendemos o design como um produto cultural, fruto de um processo coletivo e contínuo (Cheryl Buckley, 1986 e 2020), que leva em conta códigos tanto estéticos quanto sociais. Da mesma maneira, o gênero é uma construção coletiva e posta em relação.

Pensado sob a perspectiva relacional, esse aspecto nos direciona inevitavelmente para as configurações existentes entre os agenciamentos, as negociações e as condições sócio-históricas de acesso às práticas profissionais. A teórica Teresa de Lauretis (1994, p. 215) escreve que há múltiplos sistemas interligados - relações de trabalho, de classe, de raça/etnia - que configuram o contexto social e o gênero atravessa todos eles. Ao traçar um panorama da história das mulheres e das relações de gênero no Brasil, as pesquisadoras Joana Pedro e Rachel Soihet (2007) afirmam que, nos anos 1990, a dimensão gênero se torna central na compreensão da necessidade de elaborar uma narrativa histórica não apenas como reparação - com as mulheres em uma categoria separada -, mas também em relação com a história hegemônica. A categoria "mulheres" passa a ser compreendida como um conjunto heterogêneo ${ }^{12}$, composta por posicionamentos e práticas variadas. No caso desta pesquisa, em que as trajetórias documentadas são experienciadas por mulheres, a relação entre o coletivo e os percursos individuais se torna uma maneira de refletirmos sobre o trabalho das mulheres no campo do design, assim como seus agenciamentos, negociações e trajetórias, sem considerá-las fixas e circunscritas a uma experiência única.

Nosso intuito, por meio das trajetórias de Irene Ruchti e Fayga Ostrower, é analisar a produção das artistas no campo do design a partir de um emaranhado de relações que elas estabeleceram tanto nos espaços de formação, quanto nos circuitos profissionais. Para essa investigação, consultamos os acervos do MASP e do MAM Rio, instituições em que Irene e Fayga atuaram, seja como aluna ou docente. Além dos dois museus, buscamos informações

\footnotetext{
${ }^{10}$ Segundo material elaborado pelo MAM Rio com a trajetória dos cursos e eventos organizados pelo museu, o primeiro curso ministrado por Fayga Ostrower (Composição e Análise Crítica) data de 1953. A artista ministrou aulas na instituição até 1969. Ver mais em: Elizabeth Catoia Varela (2016).

${ }^{11}$ É importante destacar os trabalhos das pesquisadoras Ana Gabriela Godinho Lima (2014), Ana Mae Barbosa e Vitória Amaral (2019), Ana Paula Cavalcanti Simioni (2007 e 2008), Marinês Ribeiro (2015), Silvana Rubino (2010) e Tatiana Perecin (2003). As autoras abordam as relações de gênero nos campo da arte, arquitetura e design.

${ }^{12}$ Nesse aspecto, também é fundamental considerar outros articuladores das desigualdades, como a classe, a raça/etnia e a sexualidade, que atravessam as experiências das mulheres e as colocam em posições diferentes no tecido social.
} 
junto ao Instituto Fayga Ostrower e ao Acervo FAU USP, onde se encontra o arquivo da loja Branco \& Preto. Realizamos ainda entrevistas com Noni Ostrower, filha de Fayga Ostrower e responsável pelo instituto da artista, e com a arquiteta Dolly Michailovska. A respeito da trajetória de Irene Ruchti, conversamos com a própria artista em diversos encontros, ocorridos entre 2017 e 2018.

\section{Trajetórias em paralelo no período de institucionalização do design no Brasil}

O design, que começava a se institucionalizar nos anos de 1950 com base nas diretrizes modernas, parecia proporcionar também às mulheres o acesso ao mercado de trabalho por meio de uma formalização do estudo e da atuação no ensino de artes e artes aplicadas. Na primeira turma da Escola de Desenho Industrial do IAC (MASP), eram nove mulheres ${ }^{13}$ para um total de 23 alunos registrados. Já entre o conselho de docentes e artistas ligados ao IAC, eram três as mulheres: Elizabeth Nobiling, Lina Bo Bardi e Klara Hartoch.

O primeiro contato da artista Irene Ruchti com o IAC-MASP foi em 1950, quando visitou São Paulo para participar do curso de férias sobre história da arte, ministrado por Pietro Bardi. Naquele momento, junto a um grupo de alunos do Instituto de Belas Artes (UFRGS), Irene fez o convite a Assis Chateaubriand para ser paraninfo da formatura de sua turma em Porto Alegre. Ela contou que foi oradora na cerimônia de formatura e que neste dia recebeu uma bolsa de estudos para fazer parte da primeira turma do Instituto de Arte Contemporânea (IAC), que se iniciaria no ano seguinte.

Chateaubriand disponibilizou outras quatro bolsas para que Tasso Corrêa, diretor do instituto em Porto Alegre à época, selecionasse alunos por meio de concurso. Irene Ruchti relata que entre os colegas selecionados para participar da primeira turma do curso de Desenho Industrial do IAC (MASP), estavam Yone Maria de Oliveira e Carlos Krebs. Em reportagem no Jornal do Rio de Janeiro (Figura 1), encontramos a relação dos cinco bolsistas que vieram do Rio Grande do Sul. Além dos mencionados por Irene, há ainda Lygia Fleck e Isolde Braus.

\footnotetext{
${ }^{13}$ São elas: Ellen Pennings, Emilie Chamie - à época Haidar -, Marion Lione Lodi, Irene Ruchti, Isolde Braus, Lygia Fleck, Maria da Glória Leme, Virginia Bergamasco e Yone Maria de Oliveira. Esses nomes estão em uma lista dos alunos que participaram da primeira turma, disponível no acervo do MASP.
} 


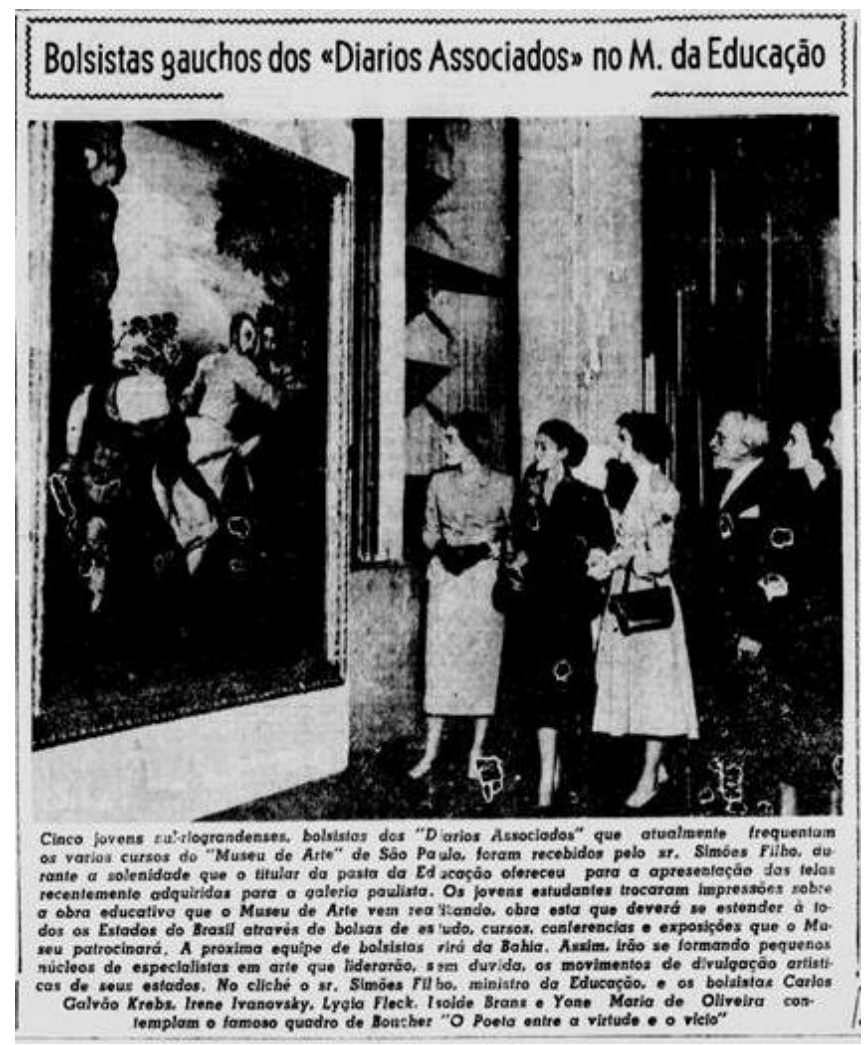

Figura 1: Irene Ruchti, de vestido preto ao centro da imagem, ao lado dos demais bolsistas gaúchos selecionados pelo MASP para o curso de Desenho Industrial, no IAC. Fonte: Jornal do Rio de Janeiro, 20 de maio de 1951.

Antes do IAC, a artista teve uma proximidade com a arquitetura durante sua formação no Instituto de Artes Plásticas. Irene relatou que sua busca nas artes plásticas estava relacionada com a elaboração do espaço, em lidar com ele: "eu posso desenhar, mas com objetivo". A intencionalidade e aplicação do desenho era algo que ela encontrava nos estudos e observações na arquitetura. A artista conta que passava uma grande parte no andar onde funcionavam as aulas de arquitetura:

Eu me formei em Belas Artes, em Porto Alegre. Porque em Pelotas, como eu estava assim fissurada em artes, apesar daqueles janelões que tinha a música da prefeitura, eu sabia de tudo, eu aprendi música lá, aprendi com as vozes de barítono do meu pai. [...] Então tudo isso me levou a me aproximar muito da música e fiquei com essa dualidade. Foi difícil destrinchar. Era a coisa do projeto, de pensar o espaço, era de desenhar tecnicamente, porque meu pai tinha me colocado nessa configuração. Depois, eu fui para Porto Alegre, para o Instituto de Belas Artes, onde os andares de Artes Plásticas estavam logo abaixo dos andares de Arquitetura. Onde eu passava mais tempo? Na arquitetura. (RUCHTI, 2018)

No segundo semestre de 1951, enquanto ainda cursava as aulas no IAC, Irene Ruchti iniciou seus projetos profissionais ao lado de Jacob Ruchti. Um dos primeiros projetos dessa época destacado pela a artista é a participação no planejamento e na supervisão das instalações internas da I Bienal Internacional de Arte de São Paulo. O arquiteto foi responsável pela estrutura de interiores dos ambientes de exposição, enquanto Irene atuava como assistente.

Já na segunda edição da Bienal, o trabalho no projeto e fiscalização da arquitetura interna continuou, dessa vez na estrutura construída nos Pavilhões das Nações e dos Estados, no Parque do Ibirapuera. Ao mesmo tempo em que ocorria a exposição, a cidade se preparava para os eventos de seu IV Centenário. A artista é convidada a integrar uma equipe responsável por 
elaborar uma apresentação de balé para essas comemorações. Entre os artistas estavam Lasar Segall, Di Cavalcanti, Cândido Portinari, Flávio de Carvalho, Darcy Penteado, Noêmia Mourão, Aldo Castro e Tomás Santa Rosa.

Nesse conjunto, é importante destacar a participação de Lasar Segall também no IACMASP, constituindo um circuito de sociabilidade recorrente no contexto artístico de São Paulo à época. Além disso, ao lado de Irene, havia mais uma mulher, Noêmia Mourão, naquele momento aos 41 anos e com uma trajetória mais consolidada. $\mathrm{O}$ projeto de cenário e figurino elaborado por Irene para o ato As Quatro Estações foi premiado ${ }^{14}$ no Rio de Janeiro pelo Museu Nacional de Belas Artes.

Sobre esse período, Irene relata que alguns artistas que passaram por São Paulo devido às Bienais visitaram o primeiro apartamento da artista e de Jacob Ruchti, com quem havia se casado em 1952, localizado na rua São Vicente de Paula, região central da cidade. Um deles foi Max Bill ${ }^{15}$, arquiteto e designer, figura central da Escola de Ulm, que fez parte do júri de premiação da II Bienal Internacional de Artes de São Paulo, em 1953. Irene destacou a importância desse dia, pois foi nessa ocasião que o designer elogiou as toalhas criadas por ela com a marca ijr com elementos em preto, dispostas no lavabo social do apartamento.

Ao se lembrar desse episódio, Irene contou que o apartamento continha muitos elementos em branco e preto e uma parede inteira em listras na sala. Ela relatou ainda que utilizou tecidos em estampas listradas para uma grande cortina. Por não gostar dos materiais têxteis tradicionais que, à época, eram usados para decoração, ela preferiu selecionar os tecidos em uma loja de artigos para camisaria masculina na rua Sete de Abril, no centro de São Paulo, mesma rua em que estava situada a Escola de Desenho Industrial do IAC-MASP.

A decoração do apartamento da rua São Vicente de Paula é destacada por Irene como experiência fundamental para a criação da Branco \& Preto Decorações e artesanatos Ltda., inaugurada em 1952 também na região central de São Paulo. Uma de suas colaborações para o espaço foi o desenho de estampas para os tecidos comercializados na loja:

Os móveis que tinha lá e estão assinados por arquitetos formados e diplomados, tinha lá uma mãozinha minha junto com eles. Nós fizemos toda a ideia dessa casa Branco \& Preto. Não teve nada onde eu não participava. Lá nós tivemos um tecido baseado em letras do alfabeto a partir da ideia de que era para fazer um tecido para quarto de criança, eu fiz esses desenhos com várias letras, eu peguei um livro, peguei várias letras, enfim, até aquela história do boi com os chifres, uma coisa divertida. Mas aquilo não era que serviria só para quartos de criança, tanto que serviu para muita gente. (RUCHTI, 2017)

Os tecidos comercializados na loja eram executados pela empresa Lanifício Fileppo S.A, que pertencia à família de Laura Forte, casada com Miguel Forte, um dos sócios da Branco \&

\footnotetext{
${ }^{14}$ Em reportagem do jornal Folha da Noite (8 de setembro de 1955), encontramos o destaque de dois prêmios atribuídos a Irene Ruchti e Lasar Segall pelo cenário e figurino desenhados para o Ballet do IV Centenário da cidade de São Paulo.

${ }^{15}$ Max Bill (1908-1994) foi aluno da Bauhaus entre os anos de 1927 e 1928. Foi professor e um dos fundadores da escola de Ulm, criada em 1953 na Alemanha, dando continuidade aos princípios da Bauhaus. Em 1951, a escultura Unidade Tripartida, de sua autoria, foi premiada na primeira edição da Bienal de São Paulo.
} 
Preto $^{16}$ (ao lado de Irene e Jacob Ruchti na Figura 2). Na imagem abaixo à direita (Figura 3), podemos observar o tecido com letras do alfabeto mencionado por Irene. A estampa desenhada pela artista aparece pendurada em destaque no interior do espaço.
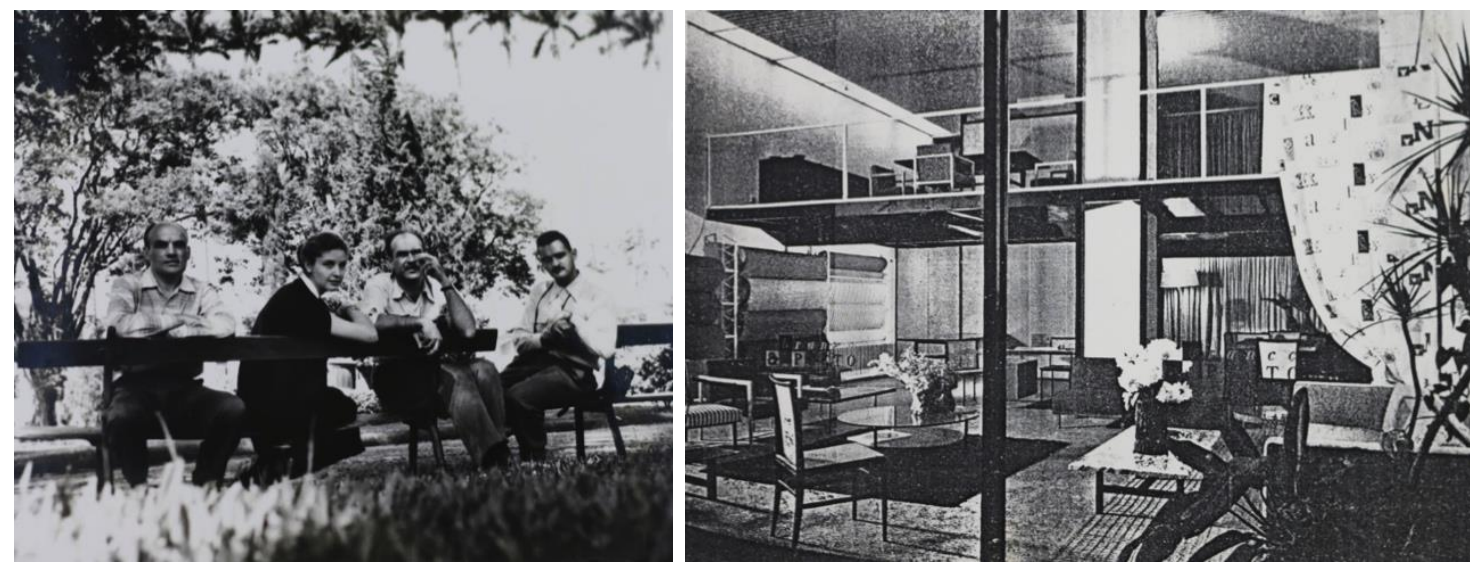

Figuras 2 e 3 : Irene e Jacob Ruchti, ao centro, ao lado de outros dois sócios da Branco \& Preto, em Campinas (imagem à esquerda). Interior da loja Branco e Preto, em São Paulo, no início da década de 1950 (imagem à direita). Fonte: Acervo FAU USP.

A loja Branco \& Preto surgiu em um contexto mais amplo dos anos de 1950, com o emprego dos princípios do moderno no mobiliário e nos demais artefatos para a casa. Segundo Maria Cecilia Loschiavo dos Santos (2015, p. 145), esse cenário se potencializou com a produção desses objetos em série. Na documentação realizada pela autora (id.), notamos o surgimento de diversas lojas e galerias, sobretudo no Rio de Janeiro e em São Paulo, que irão produzir mobiliários e decoração de interiores para as casas brasileiras.

Se a proximidade de Irene Ruchti em São Paulo era com a loja Branco \& Preto, no caso de Fayga Ostrower, sua produção era comercializada principalmente na zona Sul do Rio de Janeiro, onde se situavam muitas das lojas de mobiliário moderno. No início dos anos de 1950, Fayga trabalhou em parceria com Joaquim Tenreiro, para quem desenvolveu estampas em tecido que integraram móveis do designer para suas lojas no Rio de Janeiro e também em São Paulo (na Figura 4, a fachada da loja na capital paulista).

\footnotetext{
${ }^{16} \mathrm{~A}$ iniciativa foi uma associação entre seis arquitetos, a maioria deles egressos da Faculdade de Arquitetura do Mackenzie, incluindo Jacob Ruchti: Carlos Millan, Chen Hwa, Miguel Forte, Plínio Croce e Roberto Aflalo. A respeito da constituição e produção da Branco \& Preto, ver mais em: Marlene Acayaba (1994).
} 

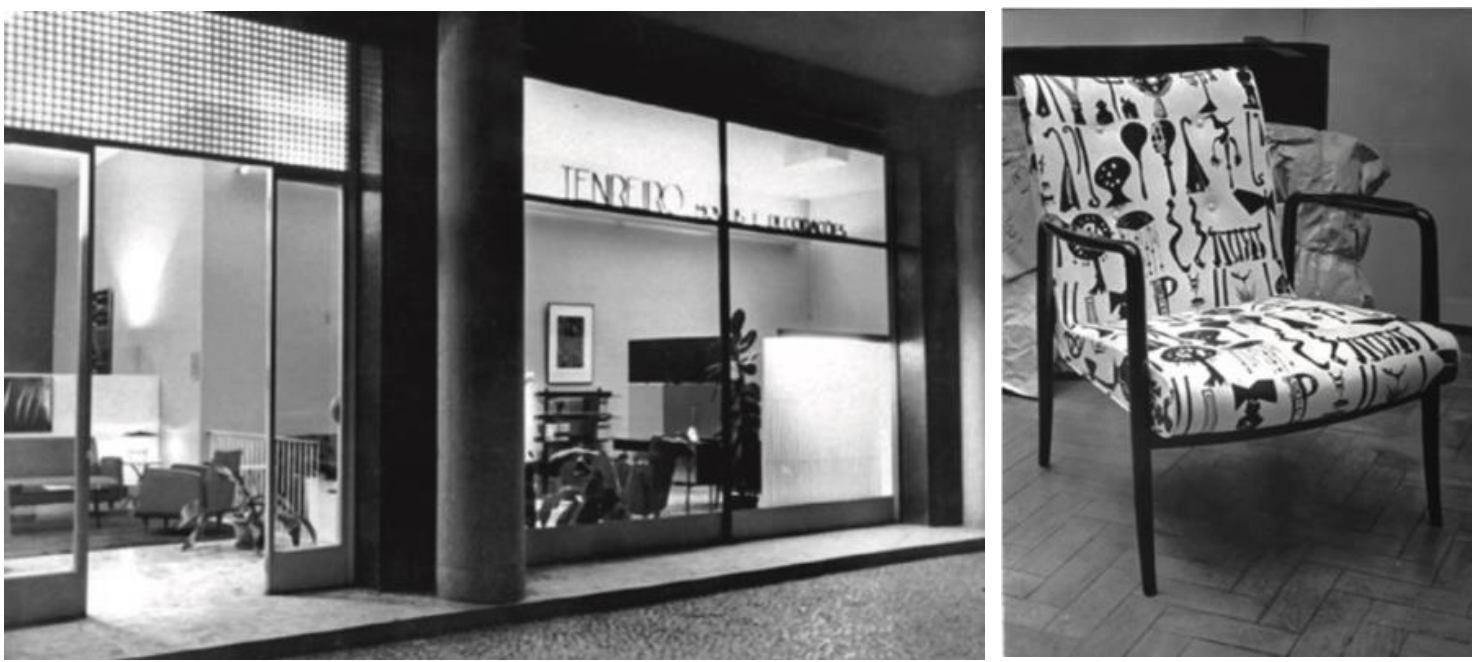

Figuras 4 e 5 : À esquerda, fachada da loja Tenreiro Móveis e Decorações, em 1953. À direita, poltrona Leve, de Joaquim Tenreiro, com tecido estampado por Fayga Ostrower. Fonte: Santos (2015, p. 118 e 119).

Em um dos registros de Santos (2015), há a menção à Poltrona Leve (Figura 5), projetada por Joaquim Tenreiro em 1942, com estampa de Fayga Ostrower. Essa peça fez parte de um projeto de reedição do objeto no início da década de 1950, época em que se concentrou a produção têxtil da artista. Outro espaço do circuito de lojas modernas cariocas que comercializava os tecidos de Fayga Ostrower foi a galeria Oca, loja do arquiteto e designer Sergio Rodrigues, inaugurada em 1955 na rua Jangadeiros. Em depoimento a esta pesquisa, a arquiteta Dolly Michailovska, colaboradora de Sergio Rodrigues por muitos anos, relatou que a loja vendia inúmeros tecidos, mas se recorda principalmente de encontrar ali os de Fayga, que, segundo ela, eram inconfundíveis.

Ainda que essas duas lojas tenham sido importantes na trajetória de Fayga Ostrower, a maior parte de sua produção em tecidos foi exposta e comercializada na loja Interiores Modernos Tecidos Ltda., do artista Décio Vieira, localizada na rua Djalma Ulrich, em Copacabana, no Rio de Janeiro. Em 1954, a artista realizou uma exposição apenas com tecidos estampados, no prédio da Associação Brasileira de Imprensa. Em reportagem publicada no jornal Correio da Manhã (22 de outubro), Fayga destaca que as padronagens expostas naquela mostra poderiam ser encontradas na Interiores Modernos. A artista detalha ainda que os tecidos eram estampados em Petrópolis, região metropolitana do Rio de Janeiro, a partir do processo de silk-screen. 


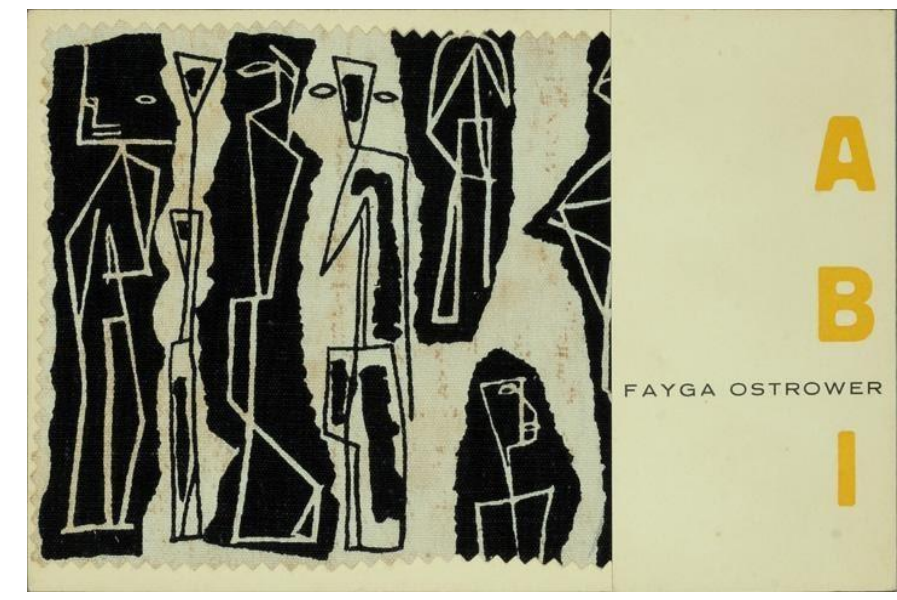

Figura 6: Capa do catálogo da exposição Fayga Ostrower, de 1954, composto com uma amostra de tecido da artista. Fonte: Instituto Fayga Ostrower.

$\mathrm{Na}$ época da exposição, Fayga Ostrower ministrava o ateliê livre de Composição e Análise Crítica no MAM Rio. Décio Vieira era seu colega na instituição, como professor de Desenho e Pintura. Ambos tiveram formação anterior no curso de Desenho e Artes Gráficas da Fundação Getúlio Vargas (FGV), ministrado por Tomás Santa Rosa (ilustração), Carlos Oswald (gravura em metal), Hanna Levy-Deinhard (história da arte) e Axl Leskoschek (xilogravura). Muitos dos professores do MAM Rio, inclusive, eram ex-alunos da FGV, como os casos de Edith Behring e Ivan Serpa. Nesse trajeto, podemos perceber que as redes construídas durante sua formação repercutem na consolidação de sua carreira profissional, com a entrada como docente no MAM Rio, mas também em um circuito de legitimação do moderno a partir de exposições de seus trabalhos artísticos.

No início dos anos de 1950, o MAM Rio conduz uma discussão importante em torno da Escola Técnica de Criação, criando um debate significativo para a ligação entre o museu e o ensino de design, mesmo que a escola em si não tenha sido concretizada. É nesse contexto que, em 1953, Max Bill realizou conferências sobre a Bauhaus e a Escola de Ulm no museu carioca (Figura 6). Esse diálogo com a recém-criada escola de design na Alemanha prosseguiu no MAM Rio durante toda a década de 1950: em 1956, com a exposição Escola Superior de Desenho de Ulm, que reunia painéis, programas didáticos e trabalhos do grupo que participou da criação da instituição alemã; e em 1959, com os cursos ministrados por Otl Aicher e Tomás Maldonado, dois dos fundadores da Escola de Ulm junto a Max Bill e a escritora Inge AicherScholl. 

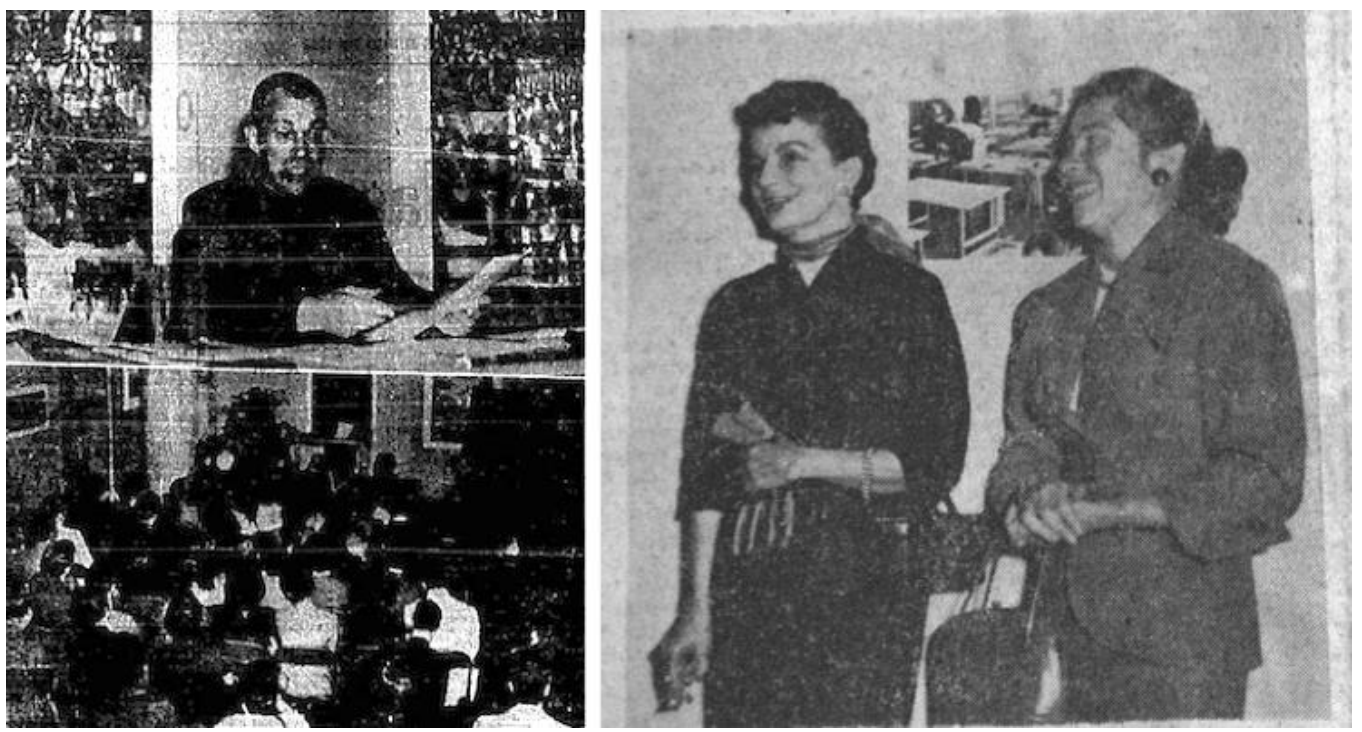

Figuras 7 e 8: Reportagem sobre a conferência ministrada por Max Bill no MAM Rio, em 1953 (imagem à esquerda). As artistas Lygia Clark e Fayga Ostrower na exposição sobre a Escola Ulm, ocorrida no MAM Rio, em 1956 (imagem à direita). Fonte: Jornal Correio da Manhã (4 de junho de 1953 e 8 de agosto de 1956).

Ao divulgar a exposição de 1956, o jornal carioca Correio da Manhã, destaca a presença de Fayga Ostrower ao lado de Lygia Clark (Figura 7), como duas das mais expressivas artistas mulheres na arte contemporânea. A matéria também aborda a proximidade de ambas as artistas com a corrente não-figurativa. Ao longo da década de 1950, podemos observar a transição de Fayga em seus trabalhos de uma arte figurativa para o abstracionismo. Esse movimento ocorreu tanto em suas gravuras aplicadas no papel quanto na produção em tecidos.

Sua proximidade com o discurso moderno não se limitou às criações artísticas, mas se estendeu também a sua atuação como docente no MAM Rio e sua participação em iniciativas que pretendiam unir a arte e a indústria. Uma dessas experiências foi o Prêmio Formiplac ${ }^{17}$, concedido pela Companhia Química Industrial de Laminados, em parceria com o MAM Rio. Sobre a elaboração de seu projeto para o concurso, a artista destacou, em matéria para a Revista Manchete (1961), que procurou uma coerência do desenho para se adequar à finalidade do material, voltado ao desenho industrial. Além disso, nesse período, Fayga também produziu estampas para a indústria têxtil Rhodia ${ }^{18}$.

Tanto a trajetória de Fayga Ostrower quanto de Irene Ruchti no campo do design se concentram ao longo das décadas de 1950 e 1960. Esse período coincide com um contexto de grande incentivo ao ensino e às práticas de design no eixo Rio de Janeiro e São Paulo a partir

\footnotetext{
${ }^{17}$ A intenção do prêmio era divulgar a utilização do formiplac, material de revestimento plástico, tanto nas artes aplicadas quanto na arquitetura. Na premiação de 1961, foram selecionados 32 artistas, com 57 trabalhos elaborados para serem aplicados em escala industrial.

${ }^{18}$ A Rhodia deu início às suas atividades no Brasil em 1919. Na década de 1950, a empresa se dedicou à produção de fios sintéticos de nylon. Ao longo da década de 1960, produziu uma série de desfiles com tecidos estampados por artistas como Aldemir Martins, Heitor dos Prazeres, Lívio Abramo, Maria Bonomi, Maria Leontina, entre outros. Sobre a produção da Rhodia desse período, ver mais em: Maria Claudia Bonadio (2005).
} 
dos museus e outras instituições de propagação do moderno. Após esse período, a centralidade do trabalho de Fayga se dará no campo da arte e de Irene na área do paisagismo.

Neste artigo, apesar de analisarmos uma porção pontual da produção dessas artistas, se comparada à quantidade de trabalho realizada por elas, é possível perceber a maneira como elas constroem uma noção do projeto moderno a partir de seus lugares sociais. Percebemos que ambas produzem, cada uma ao seu modo, um espaço de trabalho por meio de suas elaborações nos campos do design, da arte e da arquitetura.

\section{Considerações finais}

Os percursos de Fayga Ostrower e Irene Ruchti nos levam a uma série de relações de sociabilidade que elas estabeleceram a partir dos espaços de formação e dos circuitos profissionais. Nesse sentido, percebemos que o MASP e o MAM Rio atuaram como lugares de convivência e de elaboração do pensamento das artistas em torno do campo do design. No trajeto de Irene, notamos um conjunto de trabalhos construídos a partir de suas ligações com o Instituto de Arte Contemporânea do museu paulista, como é o caso do Ballet do IV Centenário, em 1954, e de sua produção em design de interiores, ao lado de Jacob Ruchti e de outros arquitetos do período. Já na trajetória de Fayga, muitos desses contatos foram acionados a partir do circuito de arte moderna da capital fluminense, centrado primeiro em sua formação inicial na Fundação Getúlio Vargas e depois em seu período como docente no MAM Rio, que expande ainda nas lojas e galerias de arte e design no Rio de Janeiro.

Nosso intuito, ao analisar as trajetórias em paralelo, foi o de buscar analisar o elo entre as negociações, os agenciamentos e o contexto social das práticas de design em seu período de institucionalização no Brasil. Dois aspectos foram fundamentais nessa análise: o primeiro é considerar as condições sociais que possibilitaram os trabalhos das duas artistas no campo do design, por meio da relação entre as práticas que elas desenvolveram, as parcerias que estabeleceram e a maneira como conduziram suas carreiras; o segundo é a relação entre o caráter individual e coletivo dos percursos, em que cada pessoa constrói seu próprio agenciamento a partir do que é colocado à sua disposição. Portanto, a partir dos espaços de trabalho das duas artistas no campo do design, foi possível relacionar os percursos profissionais ao contexto social daquele período.

\section{Entrevistas}

Anna Leonor (Noni) Ostrower, 18 de abril de 2019.

Dolly Michailovska, 9 de maio de 2019.

Irene Ruchti, 14 de novembro de 2017.

Irene Ruchti, 20 de março de 2018.

\section{Reportagens em jornais e revistas}


Jornal do Rio de Janeiro. Bolsistas gaúchos dos Diários dos Associados no Ministério da Educação, 20 de maio de 1951.

Jornal Correio da Manhã. Artes plásticas, 4 de junho de 1953.

Jornal Correio da Manhã. O público tem bom gosto, 22 de outubro de 1954.

Jornal Folha da Noite. Premiados no Rio dois cenários do conjunto, 8 de setembro de 1955.

Jornal Correio da Manhã. Duas artistas na exposição de Ulm, 8 de agosto de 1956.

Jornal Correio da Manhã. Interiores Modernos Tecidos Ltda., 17 de abril de 1957.

Jornal Correio da Manhã. As mulheres no prêmio Formiplac, 3 de junho de 1961.

\section{Referências}

ACAYABA, Marlene. Branco \& Preto: uma história de design brasileiro nos anos 50. São Paulo: Instituto Lina Bo e P. M. Bardi, 1994, 112 p.

AMARAL, Vitória; BARBOSA, Ana Mae (org.). As mulheres não devem ficar em silêncio: arte, design e educação. São Paulo: Editora Cortez, 2019, 440 p.

BONADIO, Maria Claudia. O fio sintético é um show! Moda, política e publicidade Rhodia S.A. (1960-1970). Tese (Doutorado em História), Instituto de Filosofia e Ciências Humanas, Universidade Estadual de Campinas, 2005.

BUCKLEY, Cheryl. Made in Patriarchy: Toward a Feminist Analysis of Women and Design. Design Issues, vol. 3, n. 2, p. 3-14, 1986.

BUCKLEY, Cheryl. Made in Patriarchy II: Researching (or Re-Searching) Women and Design. Design Issues, vol. 36, n. 1, p. 19-29, 2020.

CARDOSO, Rafael. O design brasileiro antes do design: aspectos da história gráfica, 1870-1960. São Paulo: Cosac Naify, 2005, 360 p.

LAURETIS, Teresa de. A Tecnologia do Gênero. In: HOLLANDA, Heloísa Buarque. Tendências e Impasses: o feminismo como crítica da cultura. Rio de Janeiro: Rocco, 1994. Parte III, p. 206-241.

LEON, Ethel. IAC. Instituto de Arte Contemporânea. Escola de desenho industrial do MASP (1951-1953). Dissertação (Mestrado em Arquitetura e Urbanismo), Faculdade de Arquitetura e Urbanismo, Universidade de São Paulo, 2006.

LIMA, Ana Gabriela Godinho. Arquitetas e arquiteturas da América Latina do século XX. São Paulo: Altamira Editorial, 2014, 116 p.

NIEMEYER, Lucy. Design Do Brasil: origens e instalação. Rio de Janeiro: Editora 2AB, $1997,136 \mathrm{p}$.

PEREIRA, Juliano A. Lina Bo Bardi: Bahia, 1958-1954. Uberlândia: EDUFU, 2008, xxx p.

PERECIN, Tatiana. 2003. Azaléias e mandacarus. Mina Klabin Warchavchik, paisagismo e modernismo no Brasil. Dissertação (Mestrado em Arquitetura e Urbanismo), Escola de Engenharia de São Carlos, Universidade de São Paulo, 2003.

RUBINO, Silvana. Corpos, cadeiras, colares: Charlotte Perriand e Lina Bo Bardi. Cadernos da Pagu, n. 34, p. 331-362, 2010. 
RUCHTI, Valeria. Jacob Ruchti: a modernidade e arquitetura paulista (1940-1970). Dissertação (Mestrado em Arquitetura e Urbanismo), Faculdade de Arquitetura e Urbanismo, Universidade de São Paulo, 2011.

SANT'ANNA, Sabrina. Construindo a memória do futuro: uma análise da fundação do Museu de Arte Moderna do Rio de Janeiro. Tese (Doutorado em Ciências Sociais), Instituto de Filosofia e Ciências Sociais da Universidade Federal do Rio de Janeiro, 2008.

SANTOS, Maria Cecilia Loschiavo dos. O móvel moderno no Brasil. São Paulo: Studio Nobel, Edusp/Fapesp, 2015, 264 p. [Primeira publicação: 1995].

SANTOS, Marinês Ribeiro. Questionamentos sobre a oposição marcada pelo gênero entre produção e consumo no design moderno brasileiro: Georgia Hauner e a empresa de móveis Mobilinea (1962-1975). Caderno aTempo, Barbacena: EdUEMG, 2015.

SIMIONI, Ana Paula Cavalcanti. Regina Gomide Graz: modernismo, arte têxtil e relações de gênero no Brasil. Revista do Instituto de Estudos Brasileiros, v. 45, p. 87-106, 2007.

SIMIONI, Ana Paula Cavalcanti. Profissão Artista: Pintoras e Escultoras Acadêmicas Brasileiras. São Paulo: FAPESP, 2008.

SOIHET, Rachel; PEDRO, Joana M. A emergência da pesquisa da História das Mulheres e das Relações de Gênero. Revista Brasileira de História, São Paulo, v. 27, n. 54, p. 281-300, 2007.

TAVORA, Maria Luisa Luz. O Campo Artístico da Gravura em São Paulo: Ensino, Produção e Circulação-1950/70. Anais do XXXVII Colóquio do Comitê Brasileiro de História da Arte, Salvador, p. 396-403, 2017.

VARELA, Elizabeth Catoia (coord.). Trajetória: cursos e eventos. Rio de Janeiro: Museu de Arte Moderna do Rio de Janeiro, 2016, 148 p.

\section{Sobre o autor}

\section{Ana Julia Melo Almeida}

Doutoranda pelo Programa de Pós-Graduação em Design da FAU USP (bolsa Fapesp n ${ }^{\circ}$ 2018/00487-0), com estágio doutoral na Ehess-Paris (França, 2019/2020). Membro do grupo de pesquisa Por um design relacional (USP). Atualmente, se dedica à pesquisa nas seguintes áreas: histórias das relações de gênero, mulheres e design, artefatos têxteis, design brasileiro.

https://orcid.org/0000-0002-3265-8275

\section{Maria Cecilia Loschiavo dos Santos}

Professora Titular de Design da Universidade de São Paulo e Bolsista de Produtividade em Pesquisa do CNPq. Tem experiência na área de Design, com ênfase nos seguintes temas: design, design para a sustentabilidade, design brasileiro, design social, exclusão sócio espacial, moradores de rua, catadores de recicláveis. https://orcid.org/0000-0001-9216-4421 